\title{
LA Cosmovisión FEMINISTA COMO ANTÍDOTO \\ DE LA ACTIVIDAD PUNiTIVA Y REPRESIVA ESTATAL
}

Una reflexión sobre la etapa de crisis económica y política en

Catalunya $^{1}$

\section{Clara Camps ${ }^{2}$}

Resumen: La crisis económica y social que se manifestaba en 2009 en el Estado Español y la Europa Sur se acabaría convirtiendo en una crisis política y territorial muy profunda que ha dado lugar a un ciclo de conflictividad social que se ha manifestado de forma muy clara en Catalunya. También ha sido en estos mismos años cuando el movimiento feminista ha emergido con fuerza, y ha extendido una nueva cosmovisión política. Ante los anhelos emancipadores y democratizadores que han ido manifestando diversos movimientos sociales $(15 \mathrm{M}$, movimientos sociales contra la austeridad, movimientos a favor de la vivienda digna, el feminismo, el movimiento por la autodeterminación, etc.), durante estos años, el Estado ha puesto en marcha su maquinaria represiva. Diversas luchas y estrategias antirrepresivas que reflejan ideas y prácticas del movimiento feminista

1 Las aportaciones de este texto nacen de algunos de los resultados de investigación del proyecto financiado por Institut Català Internacional por la Pau que lleva como título: "Conflicte a Catalunya i repressió política" (2.017 RICIP) que se está trabajando en el marco del Grupo de investigación Copolis "Bienestar, comunidad y control social" (Universidad de Barcelona).

2 Profesora de la Universitat Barcelona y Universitat de Girona.

GrupInteruniversitari Copolis "Benestar, comunitat i control social" 
han sido la respuesta a la actividad punitiva del Estado. Con todo, la misma cosmovisión feminista nos deja abierta la posibilidad de repensar la actividad represiva del Estado en clave de género y de plantear una nueva cultura antirrepresiva.

Palabras clave: Feminismo; Represión estatal; Crisis económica

Resum: La crisi econòmica i social que es manifestava el 2009 a l'Estat Espanyol i l'Europa Sud s'acabaria convertint en una crisi política $\mathrm{i}$ territorial molt profunda que ha donat lloc a un cicle de conflictivitat social que s'ha manifestat de manera molt clara a Catalunya. També ha estat en aquests mateixos anys que el moviment feminista ha emergit, amb força, tot estenent una nova cosmovisió política. Davant els anhels emancipadors i democratitzadors que han anat manifestant diversos moviments socials $(15 \mathrm{M}$, moviments socials contra l'austeritat, moviments a favor de l'habitatge digne, el feminisme, el moviment per l'autodeterminació, etc.), durant aquests anys, l'Estat ha posat en marxa la seva maquinària repressiva. Diverses lluites i estratègies antirepressives que reflecteixen idees i pràctiques del moviment feminista han estat la resposta a l'activitat punitiva de l'Estat. Amb tot, la mateixa cosmovisió feminista ens deixa oberta la possibilitat de repensar l'activitat repressiva de l'Estat en clau de gènere i de plantejar una nova cultura antirepressiva.

Paraules clau: Feminisme; Repressió estatal; Crisi econòmica

Abstract: The economic and social crisis that took place in 2009 in the Spanish State and Southern Europe would end up becoming a very deep political and territorial crisis that has led to a cycle of social conflict, as the one that has recently been happening in Catalonia. During these last years, the feminist movement has also strongly emerged, spreading a new worldview. The State has continuously used 
its repressive machinery against the emancipatory and democratizing aspirations of various social movements $(15 \mathrm{M}$, social movements against austerity, movements in favor of decent housing, feminism, the movement for self-determination, and so on). Several struggles and anti-repressive strategies reflecting ideas and practices of the feminist movement have functioned as a response to the punitive activity of the State. However, this same feminist worldview leaves open the possibility of rethinking the repressive activity of the State from a feminist point of view and proposing a new anti-repressive culture.

Keywords: Feminist movement; Repressive activity of State; Economic and crisis social

\section{Introducción}

El actual ciclo de conflictividad social que se está viviendo en Catalunya tiene antecedentes históricos, pero también tiene antecedentes más cercanos y referenciados. Aunque los primeros indicios de la situación de crisis económica en el Estado español ya se habían hecho sentir en 2009, fue en mayo de 2011 cuando estalló la serie de movilizaciones sociales que se aglutinan en el denominado movimiento $15 \mathrm{M}$.

En realidad, el 15M y los movimientos sociales que se fueron fortaleciendo-contra los desahucios, contra la reforma laboral, contra la austeridad, con los feminismos, etc.- fueron una reacción contra la gestión neoliberal de la crisis, y denunciaban claramente el nexo entre las élites económicas y los gobiernos de unos partidos políticos que, a su vez y globalmente, se sometían a estas élites.

Es precisamente también en estos años cuando el movimiento por el derecho a la autodeterminación en Catalunya fue adquiriendo fuerza. 
De hecho, este movimiento emergía con fuerza en 2010 ante al recorte del Estatuto de Catalunya, como consecuencia de la aplicación de la sentencia dictada por el Tribunal Constitucional ${ }^{3}$. Una fecha importante, para este movimiento, fue el 10 de julio de 2010, día en el que tuvo lugar la manifestación de más de un millón de personas que recorría las calles centrales de la ciudad de Barcelona con un lema principal: "Somos una nación. Nosotros decidimos".

A partir de este momento, enseguida comenzaría la serie de consultas en toda Catalunya sobre la independencia de esta comunicad del Estado Español. A partir de ahí, el movimiento por la autodeterminación no dejó de crecer y mostró toda su fuerza en las diferentes "diadas" nacionales del 11 de septiembre, en la consulta del 9 de noviembre de 2014 y en la jornada referendaria del 1 de octubre de 2017.

Si bien los diferentes movimientos sociales surgidos en esta etapa han tenido y tienen importantes diferencias, todos ellos han supuesto un importante embate e interrogación para la democracia liberal constituida: han planteado el mayúsculo interrogante sobre si la democracia era y es realmente democrática. Y es así como la democracia ha entrado en una profunda crisis de legitimidad.

La respuesta punitivista al conflicto político y social no ha hecho más que reafirmar y ratificar los planteamientos de los movimientos sociales entorno a la calidad de la democracia.

Al clamor en favor de una democracia real del 15M, de los derechos sociales y de una clara identificación y señalamiento de quiénes eran los auténticos responsables de la génesis de la crisis y de su gestión neoliberal, se respondió con una actuación contundente de los cuerpos de seguridad, con la intervención severa de la fiscalía y la judicatura en casos relacionados con la protesta, y con la aprobación de una nueva

${ }^{3}$ La sentencia del Tribunal Constitucional sobre el Estatuto de Cataluña de 2006 fue hecha pública el 28 de junio de 2010. 
regulación legislativa dirigida a restringir más aún el derecho a la protesta.

Al clamor en favor del derecho a la autodeterminación de Catalunya, el Estado español ha respondido con una mayor fuerza represiva, tal y como lo refleja la actuación policial contra los votantes pacíficos de la jornada referendaria del 1 de octubre de 2017, cuyo balance es de más de mil personas heridas; o como lo refleja también la sentencia judicial que condena a los líderes promotores (desde dentro y desde fuera del gobierno) del referéndum, acusados por los delitos de sedición y malversación, a más de cien años de cárcel ${ }^{4}$.

Ha sido también en esta etapa -que se sitúa del 2011 al 2018-que se ha producido la efervescencia, madurez y extensión de los feminismos en plural. Un fenómeno social que sólo se explica como resultado del esfuerzo de protesta y visibilización que han realizado, con anterioridad, muchas mujeres (hétero, lesbianas y trans) (G. Grenzner, 2019). Este es un movimiento que, además, ha estado y ha ido compartiendo lucha con los diferentes movimientos sociales de este período.

El movimiento feminista ha permitido abrir una nuevo marco ontológico y epistemológico que pone en el centro lo común, haciendo hincapié en la importancia de los cuidados y los afectos (R. Palop, 2019). En este artículo se considera que este nuevo marco de referencia permite hacer una relectura crítica de la actividad represiva del Estado, a la vez que permite comprender la acción antirepresiva de los movimientos sociales.

Así, este artículo pone la atención en los marcos de referencia del movimiento feminista. En este sentido, y siguiendo las clásicas

\footnotetext{
${ }^{4}$ A todo ello hay que añadirle las recientes causas judiciales abiertas, las detenciones y los encarcelamientos, y las personas heridas en manifestaciones de diferentes miembros de la sociedad civil, que han crecido exponencialmente con las protestas post-sentencia de este otoño del 2019.
} 
aportaciones de Benford y Snow (2000) se considera que los marcos de referencia son "esquemas interpretativos" compartidos y negociados colectivamente por un conjunto de actores que forman un movimiento social. Los marcos de referencia atribuyen y articulan significados que permiten condensar el mundo exterior y, así, construir definiciones de diagnóstico, de pronóstico y atribución de sentidos que guiarán la acción colectiva (Benford y Snow, 2000; Hunt, Benford y Snow, 1994).

El artículo se estructura en dos partes. En primer lugar, se apunta la necesidad de hacer una lectura feminista de la represión política. Así, se indican algunos elementos desde los cuales empezar a pensar la actividad punitiva del Estado en clave feminista. En segundo lugar, se explica cómo las ideas y las prácticas feministas que han emergido en estos últimos años han dado lugar a nuevas formas de hacer frente a la represión. Si bien se reconoce que no siempre ha sido el movimiento feminista por si solo quien ha planteado la actividad antirepresiva, sí que se sostiene que la cosmovisión feminista se ha visto reflejada en algunas de las prácticas antirepresivas que han desarrollado los movimientos sociales en esta etapa. A lo largo del artículo se destacan acciones de protesta o campañas antirepresivas, del período que se analiza, que han reflejado este marco de referencia feminista.

\section{Represión política y “acumulación por desposesión”: una lectura feminista}

La teoría feminista, igual que la teoría marxista, ha reconocido que los procesos de desposesión, que han necesitado y necesitan del neoliberalismo para su reproducción, suponen siempre un ataque a la vida y a su dignidad que, en muchos casos, se puede expresar en forma de muertes violentas (Harvey, 2004).

Existen varios procesos que hacen posible la desposesión: la precarización laboral; la privatización de los recursos que son propiedad del común; el mantenimiento de muchas personas en la 
economía informal; el extractivismo de los recursos naturales (también de las prácticas culturales que se construyen a su alrededor), y la imposición de unas formas de organización territorial que permiten la sumisión de algunos Estados a otros Estados y/o el sometimiento de muchos pueblos sin Estado (Federici, 2011, 2013; Fraser, 2014; Harvey, 2004).

Además, desde la perspectiva feminista se nos indica que estos procesos de desposesión y de acumulación de capital han sido posibles gracias a dos mecanismos esenciales: uno, mediante la reprivatización y el retorno de las tareas reproductivas a los hogares y, dos, mediante el control sobre el cuerpo de las mujeres (es decir, el control de aspectos como la maternidad, la sexualidad o la intimidad de las mujeres). (Federici, 2011).

En todo caso, es bien claro que la interposición de resistencias ante la expropiación desposeadora genera procesos que no están nunca libres de coerción, de fuerza y violencia del Estado (Harvey, 2004). De hecho, la actuación y las formas del poder punitivo estatal sólo las podemos comprender si conocemos cuál es el grado de estabilidad del orden social constituido y cuáles son los consensos sociales que se han construido a su alrededor. Consensos sociales que demuestran ser más amplios cuando existen políticas de bienestar y protectoras para la mayoría social. Parece claro, pues, que la política penal queda condicionada por dos elementos: por la acción de otras políticas públicas y por la capacidad que tengan otras instancias, como, por ejemplo, son los medios de comunicación, de transmitir ideas y crear imaginarios que estén de acuerdo con las necesidades del poder instituido.

El brazo punitivo del Estado es un mecanismo fundamental para que el proyecto neoliberal pueda instaurarse (Wacquant, 2004, 2011). La acumulación económica, que implican los procesos de desposesión en la etapa neoliberal, hace necesarios procesos de acumulación de poder. El Estado necesita hacer uso de la fuerza y la punición para controlar 
las situaciones de desigualdad y pobreza que el mismo proyecto neoliberal genera. Además, la actividad punitiva estatal se convierte en necesaria para combatir las resistencias que interpone la población organizada para reapropiarse de la extracción de aquello que nos es común. Todo ello refleja que el capitalismo no es sólo un modo de producción, sino también un modo de poder (Bichler y Nizan, 2012). Así, el proyecto neoliberal es posible gracias a una "virilización" del Estado y de sus funciones. Como nos explica Loïc Wacquant (2006, 2011), el brazo "viril" y controlador del Estado, el que representa la penalidad, se amplía y se fortalece, mientras que el brazo «maternal» y educador, representado por las políticas de bienestar y de cuidados, se debilita.

Es en tiempos de crisis económica y de aplicación de políticas de austeridad cuando el brazo "virilizado" incrementa su crecimiento y lo hace, desde el Estado, invadiendo con recortes las políticas de asistencia y protección social y manifestando su mayor capacidad de actuación severa frente a la resistencia, la movilización y la protesta.

Por otro lado, estos procesos de desposesión que implica el proyecto neoliberal necesitan de una violencia expresiva y no sólo de una violencia instrumental (Segato, 2017). Es decir, necesitan de una violencia que se exprese de forma arbitraria, fuera de una gramática jurídica, mediante las actuaciones policiales y judiciales. Saltarse la normatividad de la ley permite al Estado -O a las fuerzas paraestatales, si es el caso- comunicar que se tiene en las manos la voluntad de una colectividad (Segato, 2017). Transgredir la ley (y sus garantías procesales) se revela, pues, como elemento necesario para expresar y reafirmar la acumulación de poder económico y político.

Es en estos procesos en que se hace evidente una creciente regresión de derechos y libertades fundamentales, cuando la violencia Estatal en contra del cuerpo de las mujeres -lo que podemos designar como "represión sexuada" (Abad, 2009)- aparece como un elemento clave para transmitir quién tiene y quién puede acumular poder. 
Cuando el poder se sitúa más allá de los márgenes de la ley, los cuerpos de las mujeres se convierten en diana perfecta de demostración de la violencia y de la crueldad a la que se puede llegar. Se simboliza, de este modo, la acumulación de poder como expresión de que este poder es real, pero también como mecanismo de reafirmación ante cualquier atisbo o sombra de debilidad.

La "represión sexuada" aparece, así, como un mecanismo represivo a tener en cuenta. El cuerpo de las mujeres se convierte en un receptáculo de mecanismos punitivos, tanto procedentes de la violencia política que se aplica a los hombres como procedentes de una dimensión cultural que pretende construir un determinado concepto de feminidad (Abad, 2009; Nash, 2013).

Esta misma "represión sexuada" consigue alimentar un paisaje de crueldad y cuando se naturaliza disminuye los sentimientos de empatía (Segato, 2017). Es el paisaje de crueldad el que crea miedo, paralización social, genera rupturas comunitarias y puede llegar a romper resistencias construidas colectivamente. Se trata, así, de crear un paisaje que permita que el extractivismo y la desposesión puedan seguir su camino.

Así pues, la "virilización" del Estado no solo se produce por medio del aumento de su actividad punitiva, sino también mediante los procesos de desposesión de recursos comunes (como la sanidad, la energía, los servicios sociales o la educación), cuya consecuencia inmediata es el incremento de la actividad de cuidado en los hogares, todavía hoy normalizada como responsabilidad de las mujeres. En definitiva, mientras el aparato punitivo vigila, detiene y encierra, las mujeres quedan más sometidas a sus espacios de encierro tradicional: el matrimonio, la familia y el hogar (Francés y Restrepo, 2019).

Esta "virilización" del Estado necesita de la recuperación de un discurso neoconservador. Una retórica sobre la importancia de la ley, del orden social y el orden público que justifica las formas más severas de castigo coge fuerza. A esta retórica se suma un discurso de la 
responsabilidad individual y de la ética del trabajo que justifica recortes de servicios básicos y reformas que implican regresiones de derechos en el mercado laboral.

A estos dos discursos, se le añade el discurso ideológico de la familia como garantizadora del hecho que la reproducción y el cuidado estén en manos de las mujeres. La retórica de valores de la familia tradicional, de la biparentalidad y de la importancia de lo heteropatriarcal va ocupando espacio (Ezquerra, 2012). Así, el discurso neoconservador se convierte en un aliado imprescindible de un neoliberalismo exacerbado.

Una clara muestra del incremento de este neoconservadurismo en el Estado español, en el período al cual se refiere este artículo, fue la propuesta en 2013, del Partido Popular, de anteproyecto de la Ley de Protección de la Concepción y Derechos de la Mujer Embarazada, que suponía un importante retroceso respecto la primera ley del aborto aprobada en democracia en el Estado español. El rechazo social y el empuje de los colectivos feministas hicieron que el proyecto se tuviera que retirar, aunque se terminó limitando el derecho al aborto de las menores de 16 y 17 años.

La movilización contra este proyecto de ley supuso la apertura de causas contra activistas feministas. La iglesia, en alguna ocasión, y algunas asociaciones católicas, como la Asociación Enraizados en Cristo y en la Sociedad o la Asociación de Abogados Católicos pasaron a desempeñar un papel clave como acusaciones particulares en estos procesos judiciales.

Además, la aprobación de la Ley de Seguridad Ciudadana en 2015 también supuso un aviso para las activistas feministas. La ley paso a contemplar como infracción grave "la perturbación de la seguridad ciudadana en actos solemnes y en oficios religiosos" (artículo 36.2) cuando no constituyera una infracción penal. La misma Ley pasó a contemplar importantes penas-multa para las trabajadoras sexuales. A todo esto, se añaden las represiones contra las mujeres y las activistas 
feministas que se han ido incrementando a través de la violencia online, el hostigamiento y el abuso a través de las redes.

La "virilización" del Estado ha ido alentando un discurso misógino y conservador que se ha expresado sin tapujos mediante organizaciones de extrema derecha que han ido cogiendo fuerza. El mayor ejemplo de esto ha sido la irrupción del partido de ultraderecha Vox en el Congreso Español, con 24 escaños en abril de 2019 y con 52 escaños en las elecciones de noviembre también de 2019.

Vox se ha referido públicamente a la "ideología de género", el "hembrismo" y el "yihadismo de género". En su programa han incluido como medidas a tomar: derogar la Ley de Violencia de Género, eliminar el aborto y las operaciones de cambio de sexo de la sanidad pública, "suprimir órganos feministas" o eliminar las cuotas de las listas electorales. En definitiva, el discurso neoconservador que se ha propulsado desde la propia estructura estatal ha ido alentando a una extrema derecha misógina y machista que ahora, tras las últimas elecciones generales de noviembre de 2019, tendrá el altavoz del Congreso de los Diputados

\section{La cosmovisión feminista como oportunidad antirepresiva}

La lucha contra el patriarcado implica la confrontación con todas aquellas represiones y dominaciones a las que han estado sometidas las mujeres. Esta lucha también se ha expresado como resistencia a las obligatoriedades e imposiciones del Estado.

El feminismo incluso ha planteado una pugna con el propio Estado cuando ha denunciado que muchos de sus mecanismos reflejan estructuras de dominación patriarcal, incluso cuando ofrecen medidas de protección para las mujeres (Fraser, 2015). De hecho, es el feminismo el que ha señalado que el Estado se ha construido sobre una división fundacional según la cual el espacio público es masculino y el privado femenino, con todas las consecuencias que esto conlleva. 
Así, el marco de referencia feminista ha generado un espacio para la emancipación colectiva. Un espacio ideológico que permite pensar en la construcción del común y que es capaz de someter a crítica la desposesión del mercado y la dominación del Estado.

De acuerdo con Francés y Restrepo (2016, 2019), el sistema punitivo y el patriarcal comparten rasgos que crean semejanzas entre los dos sistemas. Pero la cosmovisión feminista -además de oponerse al patriaracado- se opone a la actividad punitiva del Estado. De manera más concreta, como vamos a tratar de argumentar, la cosmovisión feminista se opone a la materialidad y el simbolismo del aparato represivo y al relato que pretende legitimar su acción.

\subsection{Ante el desprecio a la vida, el clamor en favor de la dignidad de la vida}

Ante el desprecio por la vida en que se fundamenta el aparato represivo del Estado, y también el patriarcado (Restrepo y Francés, 2016; Francés y Restrepo, 2019), el feminismo significa la reivindicación de la vida digna.

En los momentos culminantes de la crisis económica en el Estado español, y ante la falta de asunción de políticas de protección y ante las políticas de austeridad, el movimiento feminista denunciaba que el tiempo de los cuidados -imprescindibles para la vida humana y siempre a cargo de las mujeres- acababa siendo el trabajo invisible que amortiguaba el golpe que había supuesto la crisis y su gestión (G. Grenzner, 2012).

El feminismo ayudaba a ver que el tiempo que no computaba para el capital era precisamente el tiempo que, en última instancia, nos protegía del poder del capital. De este modo, nos revelaba que los humanos somos dependientes y vulnerables y que, por ello, necesitamos afectos y cuidados a lo largo de nuestra vida.

Ha sido también la tenaz lucha feminista de estos últimos años, la que ha conseguido poner en la agenda pública la cuestión de la violencia 
machista. A partir de 2017, se daba un paso histórico a escala mundial y se iniciaba un nuevo ciclo que visibilizaba, más que nunca, la lucha contra las todas las formas de violencia machista (G. Grenzner, 2017). En el marco de Catalunya, y del Estado español, el caso de la violación en grupo en las fiestas de San Fermín de 2016 fue clave para denunciar que violar no es un acto patológico de un individuo, sino que la «cultura» de la violación y el terror sexual forman parte de una estructura social e institucional que quiere a las mujeres solas y bajo control.

Reconocer la violencia machista como un elemento estructural en el mundo del capital permite al feminismo explicar los vínculos entre violencia machista y capitalismo patriarcal. La violencia machista es la expresión más íntima de desposesión y de expropiación de la vida de las mujeres en su sentido más profundo. Es esta violencia la que logra, a través de la amenaza y el miedo -en los espacios más íntimos y también en el espacio público-, aislar, fragmentar, dividir e incluso disociar a las mujeres de sí mismas, además de desposeerlas de autonomía y de libertad. Esta es la denuncia del feminismo, pero supone también una clara denuncia de aquella violencia estatal que quiere lograr la desposesión de los recursos naturales, de los medios de subsistencia, de las prácticas culturales o de las formas organizativas de las comunidades.

El feminismo es una denuncia de la desposesión material de nuestras vidas y de la desposesión de los vínculos, cuidados y afectos que la hacen posible. No hace, pues, solamente referencia a la subsistencia material, sino también a la necesidad de que la vida sea digna de ser vivida.

Pero, ¿cuáles han sido las estrategias antirepresivas que han puesto la vida, los vínculos y los afectos en el centro de atención?, ¿’en medio de qué acontecimientos se han dado tales estrategias?:

- Entre el año 2012 y el 2013, se hicieron visibles las campañas antirepresivas del caso de Ester Quintana, el de Juan Andrés Benítez y 
el de los jóvenes del 4F. Todas ellas fueron muy significativas para explicar ejemplos prácticos de reparación del daño y de dignificación de las personas y los colectivos represaliados. La respuesta antirepresiva después de los hechos del 1 octubre de 2017 también destaca por el hecho de ser muy significativa en este sentido.

En estas luchas antirepresivas destacan tres ejes de trabajo que permitieron la dignificación de la vida de las personas represaliadas y la reparación del daño: la comunicación, la ocupación y la recuperación del espacio público, y la denuncia de los casos en sede judicial.

En el aspecto comunicativo, el "caso Ester Quintana” destaca por su potente campaña comunicativa, capaz de generar empatía con el dolor sufrido y basada en el apoyo mutuo y el cuidado como pilares fundamentales.

Para situar al lector, Ester Quintana había perdido un ojo debido a una bala de goma que habían disparado los Mossos de Esquadra cuando volvía a su casa después de la manifestación del 14 de noviembre de 2012. Una huelga que se posicionaba en contra de la reforma laboral realizada por el Partido Popular en aquel momento.

Después de que Ester perdiera el ojo, la plataforma "Ojo con tu Ojo", realizó una campaña de difusión de fotografías que exhibían a una variedad de personas cuyo nexo común era el "parche en el ojo". A partir de esta este momento empezaron a aparecer personajes públicos con el parche en el ojo y diversas aportaciones artísticas en la misma dirección de promover redes en solidaridad con Quintana y en favor de la prohibición de las balas de goma.

Esta campaña comunicativa -que rompía con el estigma construido del manifestante "antisistema"- propició la deslegitimación de las instituciones y de la policía catalana, además de que las balas de goma fueran prohibidas en el Parlament de Catalunya.

- Así mismo, desde el punto de vista comunicativo (y como un claro ejemplo de trabajo antirepresivo para la reparación del daño) en el 
período de nuestro análisis destaca el documental Ciutat morta, con el que se denunciaba el caso de los jóvenes del 4F.

El documental ${ }^{5}$ explica cómo la carga policial en un teatro ocupado en el que se estaba celebrando una fiesta acababa con uno de los policías, que iba sin casco, gravemente herido por el impacto de una maceta. El documental explicaba cómo se había condenado, sin pruebas y de forma arbitraria, a unos cuantos jóvenes por una estética que se asociaba al movimiento "okupa" de la ciudad, a la vez que demostraba cómo la detención y el encarcelamiento de Patricia Heras estaba también relacionado, también, con una serie de estereotipos de género. Este documental implicó dos acciones de ocupación del espacio público. La primera aparición de este documental fue el 8 de junio de 2013 y conllevó, además, la ocupación del Palacio del Cine de Via Laietana. El cine fue rebautizado como Cinema Patricia Heras. En la misma noche de la emisión, cuando terminaba el documental, cientos de personas consternadas se reunían en la plaza Sant Jaume, se guardaba silencio y se encendían velas. La ocupación y recuperación del espacio aparecía como estrategia de dignificación de las personas reprasaliadas y de reparación del daño.

- En una línea parecida destaca el caso de Juan Andrés Benítez. El 5 de octubre de 2013, en la calle Aurora del barrio del Raval de Barcelona, moría un hombre, Juan Andrés Benítez, a manos de la policía catalana, concretamente a manos de los agentes de policía de la comisaría de Ciutat Vella.

La Plataforma Reraguarda en Moviment, junto con el colectivo LGBTI de la ciudad y otros colectivos del barrio del Raval, tendría un papel muy relevante en la denuncia del caso Benítez. Se formaría la Plataforma Justicia Juan Andrés, en la cual también tendrían un papel clave otras

${ }^{5}$ El documental Ciutat Morta impactaba en las pantallas de TV3 el día 17 de enero de 2015, y sirvió para abrir un debate sobre el proceso de detención y condena, sobre el abuso policial y sobre sus condiciones de impunidad en su actuación. 
personas afectadas por la represión policial, como Ester Quintana. La recuperación del espacio público también fue, en este caso, una forma de dignificar y denunciar la muerte de Juan Andrés Benítez. En el primer aniversario de su muerte se ocupó un espacio en el barrio del Raval para que nadie se olvidara de lo sucedido. Se trata del Ágora Juan Andrés Benitez, que ha permitido recuperar el tejido social del barrio y dotarlo de un espacio liberado y autogestionado para el encuentro y el debate sociales, recordando los abusos policiales que han existido y existen en el barrio.

El uso del espacio para denunciar la represión y dignificar la lucha permite además reivindicar el derecho a la memoria. Con este ejercicio no solo se trata de poner en el centro un hecho de pasado, sino que permite resignificarlo, dar un sentido a un colectivo humano que ha sido represaliado y que comparte ciertos ideales, y delimitar claramente lo que no puede volver a suceder. Un último ejemplo de recuperación del espacio y de reivindicación de la memoria se ha dado con la denominación "1 de Octubre" ${ }^{6}$ de calles y plazas de distintas ciudades catalanas, tras la agresión policial a miles de ciudadanos cuyo único delito fue ir a votar.

Finalmente cabe destacar que la denuncia del abuso y las agresiones policiales ante sede judicial ha sido otra de las estrategias que han usado los movimientos sociales para dignificar a las personas represaliadas y para poner en evidencia la impunidad policial.

Las denuncias a la policía de los "casos Quintana y Benítez" fueron fundamentales, porque penetraron en la opinión pública y consiguieron hacer mediáticamente visible que los cuerpos policiales también podían acabar en el banquillo de los acusados; a la vez, ponían en evidencia que la impunidad policial es una realidad. Las personas víctimas de la violencia policial del 1 de Octubre tampoco han dudo en

${ }^{6}$ https://directa.cat/els-carrers-que-seran-sempre-de-11-doctubre/ 
denunciarla, y en octubre de 2019 había 120 policías nacionales y guardias civiles imputados.

\subsection{Ante la vulnerabilidad como espacio para la represión, la vulnerabilidad como eje articulador de una nueva sociedad}

Ante la consciencia pública de que el cuerpo y la mente humana son vulnerables, el aparato represivo del Estado, igual que el patriarcado, amenaza, agrede y violenta aquellos cuerpos desobedientes. En cambio, para el feminismo, el reconocimiento de la vulnerabilidad debe ser el punto de partida y el foco de construcción de un nuevo sistema social y económico.

Como descifra el feminismo, el cuerpo -y también la mente de las mujeres y de aquellas personas que transgreden más claramente el sistema sexo-género- se convierte en un espacio violentado y agredido por la masculinidad. La vulnerabilidad -que supone ser cuerpo humano- es la condición para que la violencia machista pueda someter, controlar y violentar. Más allá de que el cuerpo es espacio de vulnerabilidad en sí, el sistema sexo-género incrementa la vulnerabilidad de aquellas personas que transgreden las normas heteropatriarcales porque las estigmatiza, las discrimina y/o las excluye.

Mientras que esta es la realidad del patriarcado, el marco de referencia feminista ha sido capaz de poner en el foco la vulnerabilidad. En consecuencia, ha concebido el cuidado como un rasgo necesario y universal de las relaciones humanas, eliminando el estigma negativo que pesa sobre él.

El feminismo ha asumido la vulnerabilidad y la normalidad de la dependencia entre los humanos. Las necesidades humanas no pueden desligarse de los bienes relacionales, de los vínculos y de las interdependencias con las otras personas (Herrero, 2016). Tampoco estas necesidades pueden desligarse de la relación ecodependiente que los humanos tenemos con los recursos naturales del planeta Tierra 
(Herrero, 2016). Así, pues, la vulnerabilidad se lee desde el feminismo de forma inversa a como lo hace cualquier sistema represivo: es el espacio humano a proteger, y también debe ser el centro desde donde pensar y construir el orden de prioridades de una nueva organización social.

En el período que aquí se analiza, las luchas y campañas antirepresivas referenciadas han puesto precisamente su enfoque en la vulnerabilidad. Reconociendo el cuerpo como espacio de vulnerabilidad, se ha ido incorporando la idea y la necesidad de introducir los cuidados en las luchas y asumir los límites y las propias vulnerabilidades para hacer más sostenibles estas luchas.

Es esta cosmovisión feminista la que ha permitido superar el tratamiento de la represión sólo como una cuestión política o jurídica. Es un enfoque psicosocial que se ha ido extendiendo como forma de protegerse y de hacer frente a la represión; el objetivo es interpretar, comprender y abordar los daños personales, colectivos y sociales sufridos por cualquier sistema de poder represivo desde su contexto político concreto y llegar a construir y fortalecer el tejido organizativo con el que protegerse. Identificar, reconocer y atender el miedo y las diferentes emociones aparece, en este sentido, como una forma de afrontar la represión. No se trata de ser héroes, sino de combatir la represión con cuidados y solidaridades, como única vía para humanizarnos al tiempo que nos defendemos.

\subsection{Contra la criminalización y la estigmatización, la dignificación de todas las vidas}

El aparato represivo del Estado es selectivo en su actuación y discrimina vidas: actúa en función de los estereotipos de corte clasista, racista, capacitista y heteropatriarcal. Por el contrario, el feminismo es un paradigma antidiscrimintorio que defiende que todas las vidas merecen ser vividas. 
El feminismo, en el período que aquí se analiza, también ha sido capaz de visibilizar a aquellos sujetos periféricos que viven importantes situaciones de opresión, discriminación y exclusión. De algún modo, el feminismo ha hecho evidente que para explicar la desigualdad se debe tener en cuenta la intersección de múltiples variables, como son el género, la clase, la etnia y el origen, la nacionalidad, el lugar de origen o el estado de salud. Así mismo, también un feminismo de corte descolonial ha ido cogiendo fuerza, destacando la importancia del antirracismo y de la crítica a la visión eurocéntrica, y haciendo evidente la intersección de conflictos que viven las mujeres más allá del género (Otero y Otero, 2019). Además, el sujeto político del feminismo ha pasado a ser "mujeres, lesbianas y trans". De este modo, ha emergido la necesidad de reivindicar todos los cuerpos e identidades que también subvierten el heteropatriarcado.

En el fondo, ha sido también el marco de referencia feminista el que ha planteado recientemente una pugna con la democracia existente. Se ha evidenciado que, si bien la ofensiva neoliberal causaba dolor y sufrimiento para el " $99 \%$ " 7 , no todos los sujetos pertenecientes a esta franja sufrían de la misma forma.

Son múltiples las subjetividades (las trabajadoras sexuales, las mujeres migrantes, las mujeres lesbianas, las mujeres autóctonas racializadas como las gitanas, las mujeres con diversidad funcional, las mujeres encarceladas, las mujeres que viven en el ámbito rural, las personas trans, etc.) que han quedado atravesadas por opresiones, exclusiones y discriminaciones y esto es lo que desde el feminismo se pone en evidencia, esto es, que las democracias existentes operan sólo dentro del marco liberal, blanco, occidental, heterosexuales y urbano. En definitiva, el feminismo ha hecho patente que los sujetos que cuentan

\footnotetext{
7 Somos el 99\% es un lema que se extendió después del 15M y que surgió del movimiento Ocuppy Wall Street. El lema reivindica los derechos de la la mayoría de la población frente la minoría más rica del mundo.
} 
en la democracia liberal no son todos, y ha evidenciado los límites que aplican en el actual concepto ciudadanía.

Esta lógica feminista antidiscriminatoria se ha hecho evidente en varias luchas antirepresivas. Con la actividad movimentística se ha demostrado que existe una selectividad penal que es posible gracias a los procesos de estigmatización y de discriminación de aquellos sujetos que están más oprimidos en nuestras sociedades.

En la etapa que se analiza, los movimientos sociales han denunciado el descontrol y la arbitrariedad del poder punitivo sobre aquellas subjetividades más estigmatizadas. Una estigmatización basada en el machismo, el racismo y el capacitismo y que permite además ir construyendo la figura de un enemigo.

Es esta figura del enemigo la que hace posible justificar la excepcionalidad penal y que facilita que las medidas excepcionales vayan quedando integradas en la propia legislación. Por lo tanto, la necesidad de construcción de un enemigo sólo se explica como la reacción defensiva para poder reprimir a las personas que atentan contra los intereses del poder o bien que afecten a elementos particularmente sensibles que tienen que ver con la imagen que la sociedad se ha construido de sí misma.

En este sentido, el "caso Benítez" denunciaba los abusos de la policía en el barrio del Raval de Barcelona y la posible presencia de la homofobia en la intervención policial. En concreto, conforme la organización antirepresiva y contra la impunidad policial iba creciendo, se hacían visibles sujetos tradicionalmente excluidos, estigmatizados y criminalizados, reseprentado aquí por un hombre gay vecino del barrio del Raval.

El documental Ciutat morta fue clave en el mismo sentido. En él se mostraba la estigmatización que se había hecho de ciertos colectivos en la ciudad de Barcelona. Una estigmatización que se basaba en una estética que identificaba a los jóvenes del $4 \mathrm{~F}$ con el movimiento "okupa" de la ciudad. 
La protagonista del documental, Patricia Heras, activista queer, estudiosa del cómic, artista post-porno, se suicidaba en 2011, en uno de sus permisos penitenciarios. El suicidio a causa del estigma era la expresión del dolor social de la transgresión y subversión de las normas y el orden establecido. Ciutat morta rompía con algunas de las ideas preestablecidas, mostraba una realidad y alertaba del peligro del estigma, del peligro de la construcción del otro como el enemigo al que hay que perseguir.

La campaña "Tanquem els CIES", la autoorganización de los "manteros" o las denuncias de las trabajadoras sexuales coinciden también en denunciar una persecución policial o administrativa "estructural", en este caso, contra los colectivos sometidos (siempre en contra de su voluntad) a las condiciones de vida de la emigración y de la prostitución.

El feminismo lucha para que no haya vidas de primera y vidas de segunda (Butler, 2016). Y pone en evidencia que la selectividad penal no es más que un síntoma de una sociedad jerarquizada, a la vez que es un mecanismo de reproducción de esta jerarquización de carácter racista, heteropatriarcal y capacitista.

\section{Conclusiones}

El miedo es seguramente el elemento fundamental para desarticular los lazos comunitarios. Además, claro está, de ser uno de los elementos nucleares del patriarcado y también de la represión política. Ante el miedo, ha sido la sororidad -y no solo la solidaridad- aquello que el feminismo ha situado en un lugar central para hacer frente a la violencia y las represiones del patriarcado. La sororidad, a diferencia de la solidaridad, no sólo implica un apoyo a las otras personas, sino que hace referencia a una relación entre las mujeres en la que existen lazos 
de reconocimiento mutuo, de identificación, de comprensividad, de afectividad y de confianza ${ }^{8}$.

Las distintas luchas antirepresivas que se pueden analizar en el período de estudio han sido capaces de revelar los lazos que nos atan a los otros y que nos componen como comunidad. En consecuencia, la represión, en muchas ocasiones, se ha convertido en una oportunidad política para dibujar y reconstruir aquellos lazos o nudos que constituyen lo que somos, y que, en definitiva, nos ligan a los otros y nos componen como comunidad (Butler, 2006).

Lo que aquí mostramos es que la emergencia y efervescencia del movimiento feminista de estos últimos años ha permitido abrir un marco de referencia que permite seguir pensando la actividad punitiva del Estado, y la represión política, desde una perspectiva de género. También que es el paradigma feminista y sus aportaciones teóricas y prácticas lo que nos permite pensar la dirección en la que puede ir la oposición frente a cualquier forma de actividad represiva, incluida la del Estado, porque la cosmovisión feminista denuncia, interpetela y pone nombre, de una manera cotidiana, relacional, global y profunda, a su violencia, a su desprecio por la vida, a sus intereses desposeedores de vida en clara alianza con el mercado, a su abuso de poder ante la vulnerabilidad humana, a su selectividad entre aquellos colectivos más estigmatizados y/o vulnerabilizados, y a su capacidad de desarticular redes y alianzas.

Las estrategias y las luchas antirepresivas, que se han manifestado en la etapa que este artículo analiza, han puesto de relieve el potencial de los valores feministas cuando estos luchan contra la represión, y han

\footnotetext{
8 Campañas concretas como "Cap dona en l'oblit" ("Ninguna mujer en el olvido") -llena de sororidad- ha sido capaz de visibilizar —en medio de la respuesta antirepresiva que se ha dado ante la represión policial del 1 de Octubre en Catalunya- que la represión también la viven las mujeres y que ello no siempre es suficientemente visible.
} 
puesto de relieve cuál es en esencia su sesgo transformador, que se ha perfilado en sus acciones para la dignificación de las personas represaliadas; en el reclamo de la reparación del daño individual y colectivo; en la exigencia del derecho y el deber de la memoria de la represión política; en la aplicación de los cuidados, los afectos y el acompañamiento piscosocial ante la represión; en la denuncia de la selectividad, arbitrariedad y desproporcionalidad penal (que se explica solo por parámetros heteropatriarcales, racistas y capacitistas), o en la importancia de generar lazos ante la represión y la necesidad de visibilizar la represión de aquellos colectivos más inivisibilizados en nuestra sociedad.

Este trabajo pretende ser, pues, una contribución para plantear la cosmovisión feminista como una herramienta práctica, pero también teórica dado que abre nuevas formas de pensar y entender la sociedad ante la cultura del castigo y las múltiples represiones que atraviesan nuestras sociedades. Porque la cosmovisión feminista es seguramente el mejor antídoto ante cualquier forma de represión (siempre implícita en los procesos actuales de desposesión capitalista y neoliberal) y es muy probablemente también un claro antídoto de las ideas de extrema derecha actualmente en ascenso.

\section{Referencias bibliográficas}

Abad, Irene. (2009). Las dimensiones de la «represión sexuada» durante la dictadura franquista. Revista de historia Jerónimo Zurita, (84), 65-86.

Robert. D. Benford. y David. A. Snow. (2000). "Framing processes and social movements: and over view and assessement". Annu. Rev. Social, 26, pp. 611-639.

Beristain, Carlos M. y Francesc Riera. (1992). Afirmación y resistencia la comunidad como apoyo. Barcelona: Virus.

Bichler, Shimshon y Jonathan Nitzan. (2012). The asymptotes of power. Real-World Economics Review, (60), 18-53. 
Butler, Judith. (2006). Vida precaria. El poder del duelo y la violencia. Paidós: Barcelona.

Ezquerra, Sandra. (2012). Acumulación por desposesión, género y crisis en el Estado Español. Revista de Economía Crítica, (14), 124-147.

Federici, Silvia. (2011). Calibán y la bruja. Mujeres, cuerpo y acumulación originaria. Madrid: Traficantes de sueños.

Federici, Silvia. (2013). Revolución en punto cero. Trabajo doméstico, reproducción y luchas feministas. Madrid: Traficantes de sueños.

Fraser, Nancy. (2014). Tras la morada oculta de Marx. Por una concepción ampliada del capitalismo. New Left Review, 86, 57-76.

Fraser, Nancy. (2015). Fortunas del feminismo. Madrid: Traficantes de sueños.

G. Grezner, Joana. (2012). Feminismos resistendo a los ajustes estructurales y la ofensiva misógina más allá de la feminización de la resistencia: alianzas feministas contra el patriarcado capitalista. En P. Ibarra \& M. Cruells (Eds.), Anuario de los movimientos sociales. Abadiño: FundaciónBetiko.

G. Grenzner, Joana. (2017). 2017: resistencia feminista local y global frente a la guerra contra las mujeres y la austeridad. En P. Ibarra \& M. Cruells (Eds.), Anuario de loa movimientos sociales (pp. 1-24). Abadiño:FundaciónBetiko.

G. Grezner, Joana. (2019). Potències, reptes i tensions dels feminismes catalans en l'actualitat. De revolució silenciosa a alternativa sistèmica. Idees, 46.

Francés, Patricia y Diana Restrepo. (2019). ¿Se puede terminar con la prisión? Críticas y alternativas al sistema de justicia penal. Madrid: Libros de la Catarata.

Harvey, David. (2004). The new imperialism acumulation by dispossession. Socialist Register, 40, 63-87.

Herrero, Yayo. (2016). Economia feminista y economía ecológica, el diálago necesario y urgente. Revista de economía crítica, 22.

Hunt, Scout; Benford, Robert, y David Snow (1994): "Marcos de acción colectiva y campos de identidad en la construcción social de los movimientossociales" En E. Laraña y J. Gusfield, coord., Los nuevos movimiento ssociales. De la ideología a la identidad (pp.221-252). Madrid, Centro de investigaciones sociológicas.

Nash, Mary. (2013). Represión, resistencias, memoria. Las mujeres bajo la dictadura franquista. Comares: Granada. 
Otero Vidal, Mercè y Montserrat Otero Vidal. (2019). Teixint els fils d'una geneologia dels feminismes a Catalunya. Idees, 47.

Palop, María Eugenia.R. (2019). Revolución feminista y políticas de los común frente la extrema derecha. Barcelona: Icaria.

Restrepo, Diana y Paz Francés. (2016). Rasgos comunes entre el poder punitivo y el poder patriarcal. Revista Colombiana de Sociología, 39(1), 21-46.

Segato, Rita. (2017). La guerra contra las mujeres. Madrid: Traficantes de sueños.

Wacquant, Loïc. (2006). Castigar els pobres. Barcelona: Edicions de 1984.

Wacquant, Loïc. (2011). Posar ordre a la inseguretat. Polarització social i recrudescència punitiva. Revista Catalana de Seguretat Pública, (24), 135148. 